OPEN ACCESS

Edited by:

Ming Jia,

Dalian University of Technology, China

Reviewed by:

Zhijiang Ye,

University of California Merced, USA

Paul Shiller,

The University of Akron, USA

${ }^{*}$ Correspondence:

Jun Qu,

Materials Science and Technology

Division, Oak Ridge National

Laboratory, P.O. Box 2008,

MS-6063,

Oak Ridge, TN 37831-6063, USA

qujn@ornl.gov

Specialty section:

This article was submitted to Engine and Automotive Engineering, a section of the journal

Frontiers in Mechanical Engineering

Received: 22 May 2015 Accepted: 09 September 2015 Published: 29 September 2015

Citation:

Barnhill WC, Gao H, Kheireddin B, Papke BL, Luo H, West BH and Qu J (2015) Tribological bench and engine dynamometer tests of a low viscosity

SAE OW-16 engine oil using a combination of ionic liquid and ZDDP

as anti-wear additives.

Front. Mech. Eng. 1:12.

doi: 10.3389/fmech.2015.00012

\section{Tribological bench and engine dynamometer tests of a low viscosity SAE 0W-16 engine oil using a combination of ionic liquid and ZDDP as anti-wear additives}

\author{
William C. Barnhill ${ }^{1,2}$, Hong Gao $^{3}$, Bassem Kheireddin ${ }^{3}$, Brian L. Papke ${ }^{3}$, Huimin Luo ${ }^{4}$, \\ Brian H. West ${ }^{4}$ and Jun $\mathrm{Qu}^{1 *}$ \\ ${ }^{1}$ Materials Science and Technology Division, Oak Ridge National Laboratory, Oak Ridge, TN, USA, ${ }^{2}$ Mechanical, Aerospace and \\ Biomedical Engineering Department, University of Tennessee, Knoxville, TN, USA, ${ }^{3}$ Shell Projects and Technology (US), Shell \\ Technology Center Houston, Houston, TX, USA, ${ }^{4}$ Energy and Transportation Science Division, Oak Ridge National Laboratory, \\ Oak Ridge, TN, USA
}

We have previously reported an oil-miscible phosphonium-organophosphate ionic liquid (IL) with an effective anti-wear (AW) functionality when added to a base oil by itself or combined with a conventional zinc dialkyldithiophosphate (ZDDP) for a synergistic effect. In this research, we investigated whether this synergy manifests in formulated engine oils. An experimental SAE OW-16 engine oil was generated containing a combination of $\mathrm{IL}$ and ZDDP with equal phosphorus contribution. The prototype engine oil was first evaluated using tribological bench tests: AW performance in boundary lubrication (BL) and friction behavior (Stribeck curves) in elastohydrodynamic, mixed, and BL. The forthcoming standard Sequence VIE engine dynamometer test was then conducted to demonstrate improved fuel economy. Results were benchmarked against those of another experimental engine oil with almost the same formulation except using ZDDP only without the IL (similar total phosphorus content). The IL-ZDDP formulation consistently outperforms the ZDDP-only formulation in friction reduction and wear protection, and results from the bench and engine tests are well correlated.

Keywords: oil-miscible ionic liquid, formulated engine oil, lubricant, anti-wear additive, engine test, fuel economy

\section{Introduction}

Reducing friction and wear is a persistent issue facing many industries, consumers, and societies around the world. The US automotive industry in particular faces increasing governmental regulation (Shiau et al., 2009) and consumer demand (Dreyfus and Viscusi, 1995) to improve the effectiveness of lubricants. Incremental improvements in lubricants can not only reduce financial losses associated with component failure, but can also conserve material, energy, and the environment. Frictional energy dissipation in internal combustion (IC) engines may cost the US nearly 1.3 billion barrels of oil annually (Holmberg et al., 2012) with engine bearing irreversibilities costing 10-15\% of total engine energy production (Tung and McMillan, 2004). Power production in IC engines depends on reciprocating, sliding surface interactions that continually vary the lubrication regime between boundary lubrication $(\mathrm{BL})$, mixed lubrication $(\mathrm{ML})$, elastohydrodynamic lubrication $(\mathrm{EHL})$ 
and hydrodynamic lubrication (HL). This range of lubrication behavior presents a twofold problem when minimizing energy dissipation at the most important piston ring cylinder liner interface: (1) higher viscosity engine oil can better counter the tendency for lubricant films to become deleteriously thinner as sliding speed decreases and temperature rises (i.e., in $\mathrm{ML}$ or $\mathrm{BL}$ ) near the top ring reversal region of a stroke, but (2) most of a piston stroke has little to no asperity contact (i.e., in EHL or HL); therefore, a lower viscosity lubricant would be preferable to reduce parasitic friction, but posts a challenge for wear protection. Novel lubricant additive formulations that allow lower viscosity engine oils, while retaining anti-wear (AW) benefits are a logical path for researchers to follow in order to resolve these issues.

Since the seminal work in 2001 (Ye et al., 2001), exploration of ILs as lubricants and lubricant additives has proliferated. These room-temperature molten salts offer low volatility, high thermal stability with ashless decomposition and can be tailored for specific properties via changes in alkyl structures. Early works involved ILs with imidazolium cations and fluorine-( $\mathrm{Mu}$ et al., 2004; Phillips and Zabinski, 2004; González et al., 2010) or boratecontaining anions (Liu et al., 2002; Chen et al., 2009), but ILs in lubrication since then have become more diverse (Bermúdez et al., 2009; Minami, 2009; Palacio and Bhushan, 2010). Progress on ILs as lubricant additives has been varied with some employing polar base stocks (Yao et al., 2009; Cai et al., 2010) to overcome most ILs' inherent insolubility in non-polar oils and others using immiscible ionic liquid (IL) emulsions or very low concentrations of ILs in non-polar base oil (Qu et al., 2006, 2009; Mistry et al., 2009; Lu et al., 2010; Qu et al., 2010; Schneider et al., 2010). Others explored using ILs as neat lubricants (Jiménez et al., 2006). ILs with quaternary alkylphosphonium cations and various anions have been investigated for beneficial tribological properties by several groups (Liu et al., 2006; Weng et al., 2007; Forsyth et al., 2008; Minami et al., 2010; Somers et al., 2010a,b; Shah et al., 2011; Libardi et al., 2013). Fully oil-miscible alkylphosphoniumorganophosphate ILs were recently developed in our chemistry lab (Qu et al., 2012, 2014; Yu et al., 2012; Barnhill et al., 2014; Zhou et al., 2014) and found to effectively decrease friction and wear in $\mathrm{BL}$ and $\mathrm{ML}$, as confirmed later by other research groups (Somers et al., 2013; Otero et al., 2014). Additionally, this family of ILs was shown to be non-corrosive and have decomposition temperatures above hydrocarbon base oils and common AW additives, such as zinc dialkyldithiophosphate (ZDDP) (Barnes et al., 2001).

More recently, we discovered remarkable synergistic effects when using a phosphonium-organophosphate IL and ZDDP together as a hybrid AW additive in gas-to-liquid (GTL) base oil (Qu et al., 2015). In this work, we investigated the tribological impact of a combination of IL + ZDDP in a prototype fully formulated engine oil using both tribological bench tests and full-scale Sequence VIE engine dynamometer tests.

\section{Experimental Methods and Materials}

The IL of interest in this work, tetraoctylphosphonium bis(2ethylhexyl) phosphate $\left(\left[\mathrm{P}_{8888}\right][\mathrm{DEHP}]\right)$, was synthesized in an organic chemistry lab at ORNL using the method outlined in our previous work (Barnhill et al., 2014) with a 93.8\% yield and
TABLE 1 | Physical and rheological properties of neat anti-wear additives. Decomposition temperature was measured in air.

\begin{tabular}{|c|c|c|c|c|c|c|}
\hline \multirow{2}{*}{$\begin{array}{l}\text { Anti-wear } \\
\text { additive }\end{array}$} & \multirow{2}{*}{$\begin{array}{l}\text { Density } \\
\left(\mathrm{g} / \mathrm{cm}^{3}\right)\end{array}$} & \multirow{2}{*}{$\begin{array}{c}\text { Decomposition } \\
\text { temperature } \\
\left({ }^{\circ} \mathrm{C}\right)\end{array}$} & \multirow{2}{*}{$\begin{array}{c}P \\
\text { content } \\
\text { (wt \%) }\end{array}$} & \multirow{2}{*}{$\begin{array}{c}\mathrm{Zn} \\
\text { content } \\
(w \mathrm{w} \%)\end{array}$} & \multicolumn{2}{|c|}{ KV (cSt) } \\
\hline & & & & & $40^{\circ} \mathrm{C}$ & $100^{\circ} \mathrm{C}$ \\
\hline $\begin{array}{l}\text { Secondary } \\
\text { ZDDP }\end{array}$ & 1.20 & 189 & 10 & 11 & 407.6 & 13.5 \\
\hline$\left[\mathrm{P}_{8888}\right][\mathrm{DEHP}]$ & 0.86 & 290 & 7.77 & 0 & 711.4 & 79.3 \\
\hline
\end{tabular}

a water content of $0.1 \%$. Oil solubility assessment for this IL was conducted by combining it with GTL $4 \mathrm{cSt}$ base oil up to a 1:1 ratio and shaking it for $1 \mathrm{~min}$. The combination was then placed into a centrifuge for $3 \mathrm{~min}$ at $13,000 \mathrm{rpm}$. No separation was evident. A commercial secondary ZDDP was provided by Lubrizol $(\mathrm{OH})$ with a zinc content of $11.0 \mathrm{wt} \%$ and phosphorous content of $10.0 \mathrm{wt} \%$. Characterization and chemical structures related to both AW additives in this work are shown in Table 1 and Figure 1 respectively. The viscosities were measured using a Petrolab MINIVIS II viscometer and the standard deviation was controlled to be $<1 \%$.

The experimental formulation (EF) in this work is a blend of GTL 4 and 8 cSt base oils with a package of additive components provided and blended by Shell Global Solutions (TX) that includes detergent, dispersant, viscosity modifier (VM), antioxidant $(\mathrm{AO})$, friction modifier (FM), pour-point depressant (PPD), anti-foam (AF) and AW additives that are detailed in Table 2. The EF is a result of a systematic study of compatibility between the IL and each additive in the package (to be reported in a separate publication). Three lubricants were tested: EF w/o AW, EF + 0.8wt\% ZDDP, and EF + $0.52 w t \%$ IL + $0.4 w t \%$ ZDDP. Lubricants were blended to adhere to International Lubricants Standardization and Approval Committee (ILSAC) GF-5/6 specifications such that phosphorus concentrations do not exceed $800 \mathrm{ppm}$. The measured phosphorus contents in $\mathrm{EF}+0.8 \mathrm{wt} \%$ ZDDP, and EF $+0.52 \mathrm{wt} \% \mathrm{IL}+0.4 \mathrm{wt} \% \mathrm{ZDDP}$ are 723 and $705 \mathrm{ppm}$, respectively. It should be noted that $\mathrm{EF}+0.52 \%$ $\left[\mathrm{P}_{8888}\right][\mathrm{DEHP}]+0.4 \%$ ZDDP was blended so each AW additive contributes roughly equal phosphorus concentration. The high temperature-high shear (HTHS) viscosity was measured using a tapered bearing simulator (Tannas Co.) and the kinematic viscosity (KV) was measured using a CAV-2100 automatic viscometer (Cannon Instrument Co.). The cold-cranking simulator (CCS) viscosity measurement was performed using a G-109-CCS-2100 model viscometer (Cannon Instrument Co.). Table 3 details the density, rheological properties, and concentrations of phosphorus and zinc for each lubricant.

A Plint TE77 (Phoenix Tribology Ltd.) tribometer was used to obtain in situ friction data and to produce wear tracks. The machine is arranged to produce an alternating sliding motion against a test material immersed in lubricant. Wear tracks were created on $25.4 \mathrm{~mm} \times 25.4 \mathrm{~mm} \times 3.175 \mathrm{~mm}$ CL35 cast iron flats (Metal Samples Company, AL, USA) rubbing against $10 \mathrm{~mm}$ AISI 52100 steel balls. Cast iron test specimens were polished with 600 grade silicon carbide abrasive paper with a unidirectional lay at $90^{\circ}$ to the sliding axis. Both steel balls and cast iron flats were 
cleaned with isopropanol and allowed to dry before submersion in lubricant. Each test was performed at $100^{\circ} \mathrm{C}$ with a normal load of $100 \mathrm{~N}$ for an overall sliding distance of $1000 \mathrm{~m}$. Scars were formed under fully sliding conditions with a $10 \mathrm{~mm}$ stroke at $10 \mathrm{~Hz}$. The point-contact ensures test conditions completely within the BL regime. Two tests were executed for each lubricant. After wear testing, balls and flats were cleaned in acetone and then isopropanol. Wear measurements were taken with a Veeco (now Bruker, TX, USA) Wyko NT9100 optical interferometer.

Scanning electron microscopy (SEM) and top-surface elemental analysis was completed using a Hitachi S-4800 (Tokyo, Japan) scanning electron microscope with EDAX (NJ, USA) silicon drift detector energy dispersive X-ray spectroscopy (EDS) capability. EDS was completed at a potential of $5.0 \mathrm{kV}$ over a time span of 1 min for each measurement.
Stribeck curves for $\mathrm{EF}+0.8 \%$ ZDDP, $\mathrm{EF}+0.52 \% \mathrm{IL}+0.4 \%$ ZDDP and SAE 20W-30 reference oil without FM or viscosity improver (same baseline oil as Sequence VIE standard) were produced by two test methods using ball-on-disk rolling-sliding on a PCS Instruments (UK) Mini Traction Machine 2 (MTM). In Method 1, twenty repeated scans were executed for the full range of speed from 2500 to $20 \mathrm{~mm} / \mathrm{s}$, while in Method 2, scans were conducted in three sections of speeds, $2500-2000 \mathrm{~mm} / \mathrm{s}$ for 5 repeats, $2000-200 \mathrm{~mm} / \mathrm{s}$ for 20 repeats, and then $200-20 \mathrm{~mm} / \mathrm{s}$ for 10 repeats. Both the ball and the disk were made of hardened AISI 52100 bearing steel. The ball had a diameter of $19.5 \mathrm{~mm}$ and hardness of $64 R_{\mathrm{c}}$. The disk had a hardness of $62.5 R_{\mathrm{c}}$. Test parameters are given in Table 4 with slide-roll ratio $(\mathrm{SRR})=\Delta U / U_{\mathrm{e}}$, where $\Delta U=U_{1}-U_{2}$ is the sliding velocity and $U_{\mathrm{e}}=\left(U_{1}+U_{2}\right) / 2$ is the mean velocity. Arithmetic average surface roughness $\left(R_{\mathrm{a}}\right)$ was

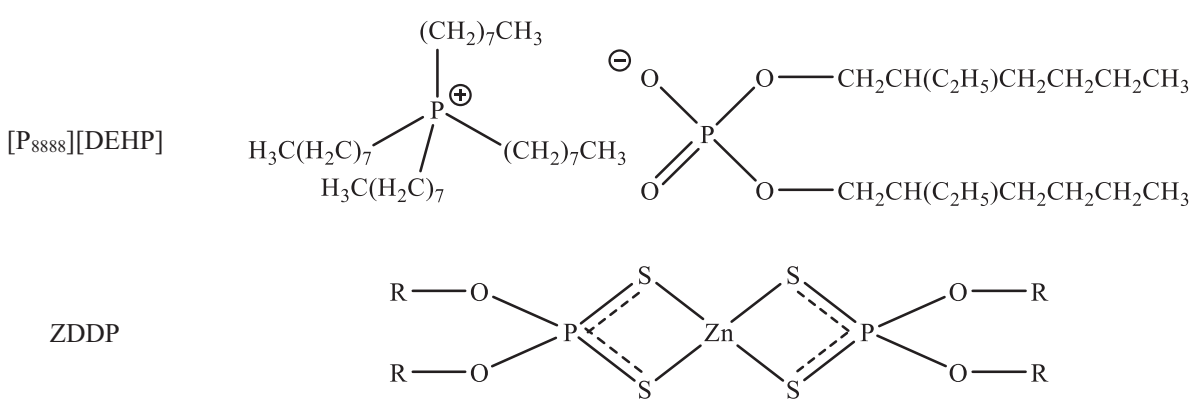

FIGURE 1 | Structures of tetraoctylphosphonium bis(2-ethylhexyl) phosphate and zinc dialkyldithiophosphate.

TABLE 2 | Additive composition of each lubricant.

\begin{tabular}{|c|c|c|c|c|c|c|c|c|c|}
\hline \multirow[t]{2}{*}{ Lubricant } & \multirow[t]{2}{*}{ Salicylate detergent } & \multirow[t]{2}{*}{ High MW dispersant } & \multirow[t]{2}{*}{ VM } & \multirow[t]{2}{*}{ AO } & \multirow[t]{2}{*}{ Organic FM } & \multirow[t]{2}{*}{ PPD } & \multirow[t]{2}{*}{ AF } & \multicolumn{2}{|r|}{ AW } \\
\hline & & & & & & & & ZDDP & {$\left[P_{8888}\right][D E H P]$} \\
\hline EF w/o AW & $3 \%$ & $2 \%$ & $2.4 \%$ & $1 \%$ & $0.8 \%$ & $0.3 \%$ & $0.03 \%$ & $0 \%$ & $0 \%$ \\
\hline $\mathrm{EF}+\mathrm{ZDDP}$ & $3 \%$ & $2 \%$ & $2.4 \%$ & $1 \%$ & $0.8 \%$ & $0.3 \%$ & $0.03 \%$ & $0.8 \%$ & $0 \%$ \\
\hline $\mathrm{EF}+\mathrm{IL}+\mathrm{ZDDP}$ & $3 \%$ & $2 \%$ & $2.4 \%$ & $1 \%$ & $0.8 \%$ & $0.3 \%$ & $0.03 \%$ & $0.4 \%$ & $0.52 \%$ \\
\hline
\end{tabular}

Percentages are on a mass basis.

TABLE 3 | Density, P and Zn content, viscosity index, and rheological data for each lubricant.

\begin{tabular}{|c|c|c|c|c|c|c|c|c|}
\hline \multirow[t]{2}{*}{ Lubricant } & \multirow[t]{2}{*}{ Density $\left(\mathrm{g} / \mathrm{cm}^{3}\right)$} & \multirow[t]{2}{*}{ P content (ppm) } & \multirow[t]{2}{*}{ Zn content (ppm) } & \multirow[t]{2}{*}{ Viscosity index } & \multirow[t]{2}{*}{ HTHS@150C (cP) } & \multirow[t]{2}{*}{$\operatorname{ccs}(\mathrm{cP})$} & \multicolumn{2}{|c|}{ KV (cSt) } \\
\hline & & & & & & & $40^{\circ} \mathrm{C}$ & $100^{\circ} \mathrm{C}$ \\
\hline EF w/o AW & 0.84 & 0 & 0 & 155 & 2.4 & 6214 & 38.9 & 7.3 \\
\hline$E F+0.8 \%$ ZDDP & 0.84 & 723 & 836 & 157 & 2.4 & NM & 38.5 & 7.3 \\
\hline$E F+0.52 \% I L+0.4 \%$ ZDDP & 0.84 & 705 & 392 & 155 & 2.4 & $N M$ & 38.8 & 7.3 \\
\hline
\end{tabular}

TABLE 4 | Test parameters for MTM Stribeck scan experiments.

\begin{tabular}{|c|c|c|c|c|c|c|}
\hline \multirow[b]{2}{*}{ Speed (mm/s) } & \multicolumn{3}{|c|}{ MTM method 1 (Figure 5) } & \multicolumn{3}{|c|}{ MTM method 2 (Figure 6) } \\
\hline & 2500-2000 & 2000-200 & $200-20$ & 2500-2000 & $2000-500$ & $500-50$ \\
\hline Speed step size (mm/s) & 250 & 200 & 20 & 100 & 100 & 50 \\
\hline Number of scans & \multicolumn{3}{|c|}{20 over entire range per scan } & 5 & 20 & 10 \\
\hline Approximate time per step (s) & \multicolumn{3}{|c|}{10} & \multicolumn{3}{|c|}{10} \\
\hline Load (N) & \multicolumn{3}{|c|}{30} & \multicolumn{3}{|c|}{30} \\
\hline Temperature $\left({ }^{\circ} \mathrm{C}\right)$ & \multicolumn{3}{|c|}{100} & \multicolumn{3}{|c|}{120} \\
\hline Slide-roll ratio (\%) & \multicolumn{3}{|c|}{100} & \multicolumn{3}{|c|}{100} \\
\hline
\end{tabular}


quantified for both sets of tests using the Wyko NT9100 for the balls and a Dektak XT stylus profilometer for the disks.

Fuel economy improvement due to the addition of IL was further assessed using FEI 1 of the impending ILSAC GF-6 Sequence VIE engine dynamometer test at Intertek Automotive Research (TX, USA). The Sequence VIE is an update to the standard Sequence VID test [ASTM D 7589 (D7589-15 A, 2015)] with increased fuel economy limits and change of the test engine to a 2012 GM Malibu 3.6 L engine. This standard testing procedure compares a test lubricant's performance with that of a SAE 20W-30 baseline lubricant over six different stages of engine operation. Each lubricant was first aged over $16 \mathrm{~h}$ of engine operation at $2250 \mathrm{rpm}$ and $120^{\circ} \mathrm{C}$ oil temperature. The first six-stage measurements (FEI 1) were then made at the conditions outlined in Table 5.

\section{Results and Discussion}

\section{Boundary Lubrication Wear and Friction}

Ball-on-flat reciprocating wear tests were performed in the $\mathrm{BL}$ regime to compare the wear protection performance between the IL-ZDDP combination and the ZDDP-only lubricant. As shown in Figure 2A, EF $+0.52 \%\left[\mathrm{P}_{8888}\right][\mathrm{DEHP}]+0.4 \% \mathrm{ZDDP}$ produced the lowest wear, at roughly $90 \%$ reduction over EF w/o AW and about $9 \%$ reduction over $\mathrm{EF}+0.8 \% \mathrm{ZDDP}$. Each data point represents an average of two repetitions per lubricant. Due to the hardness disparity between the balls and flats, ball wear volumes are on the order of two magnitudes less than flat wear volumes.
Friction results from the reciprocating-sliding bench tests are shown in Figure $\mathbf{2 B}$ and represent an averaged performance over two repetitions. The lubricant without AW had the highest steady-state friction coefficient with a final value above 0.10 . $\mathrm{EF}+0.52 \%\left[\mathrm{P}_{8888}\right][\mathrm{DEHP}]+0.4 \%$ ZDDP produced the lowest friction coefficient for the first $500 \mathrm{~m}$ of sliding, after which, both lubricants containing AW showed a similar friction coefficient around 0.08 .

\section{Wear Scar Morphology Examination and Chemical Analysis}

The wear scars produced by the two lubricants containing either ZDDP only or ZDDP + IL were examined using SEM for topsurface morphology imaging and EDS for chemical analysis. Figure 3 consists of the SEM micrographs and EDS spectra of the surface pair lubricated with EF $+0.8 \%$ ZDDP. The steel ball shows an elliptical wear pattern with relatively evenly dispersed parallel scratch patterns. The worn surfaces appear covered by dark tribofilms with some patchy areas of exposed substrate. EDS spectra provide further evidence of the tribofilms: on a surface lubricated by a ZDDP-containing oil, both mating surfaces show the presence of zinc, phosphorus, and sulfur, which could only have originated from ZDDP in the lubricant. Increased amounts of these elements on the cast iron flat may indicate a more substantial film with better coverage on this surface compared to that of the ball. Calcium is also present in trace amounts at the surface originating from the detergent in the EF. It has been shown that calcium phosphates form in a separate phase in ZDDP

TABLE 5 | Sequence VIE fuel economy engine test conditions.

\begin{tabular}{|c|c|c|c|c|c|c|}
\hline & Stage 1 & Stage 2 & Stage 3 & Stage 4 & Stage 5 & Stage 6 \\
\hline Torque (Nm) & $105.0 \pm 0.1$ & $105.0 \pm 0.1$ & $105.0 \pm 0.1$ & $20.0 \pm 0.1$ & $20.0 \pm 0.1$ & $40.0 \pm 0.1$ \\
\hline Speed (rpm) & $2000 \pm 5$ & $2000 \pm 5$ & $1500 \pm 5$ & $695 \pm 5$ & $695 \pm 5$ & $695 \pm 5$ \\
\hline Oil gallery temperature $\left({ }^{\circ} \mathrm{C}\right)$ & $115 \pm 2$ & $65 \pm 2$ & $115 \pm 2$ & $115 \pm 2$ & $35 \pm 2$ & $115 \pm 2$ \\
\hline Nominal power (kW) & 22.0 & 22.0 & 16.5 & 1.5 & 1.5 & 2.9 \\
\hline Weight factor & 0.300 & 0.032 & 0.310 & 0.174 & 0.011 & 0.172 \\
\hline Lubrication regime & & EHL/HL dominant & & More BL/ML & Some BL/ML & More BL/ML \\
\hline
\end{tabular}
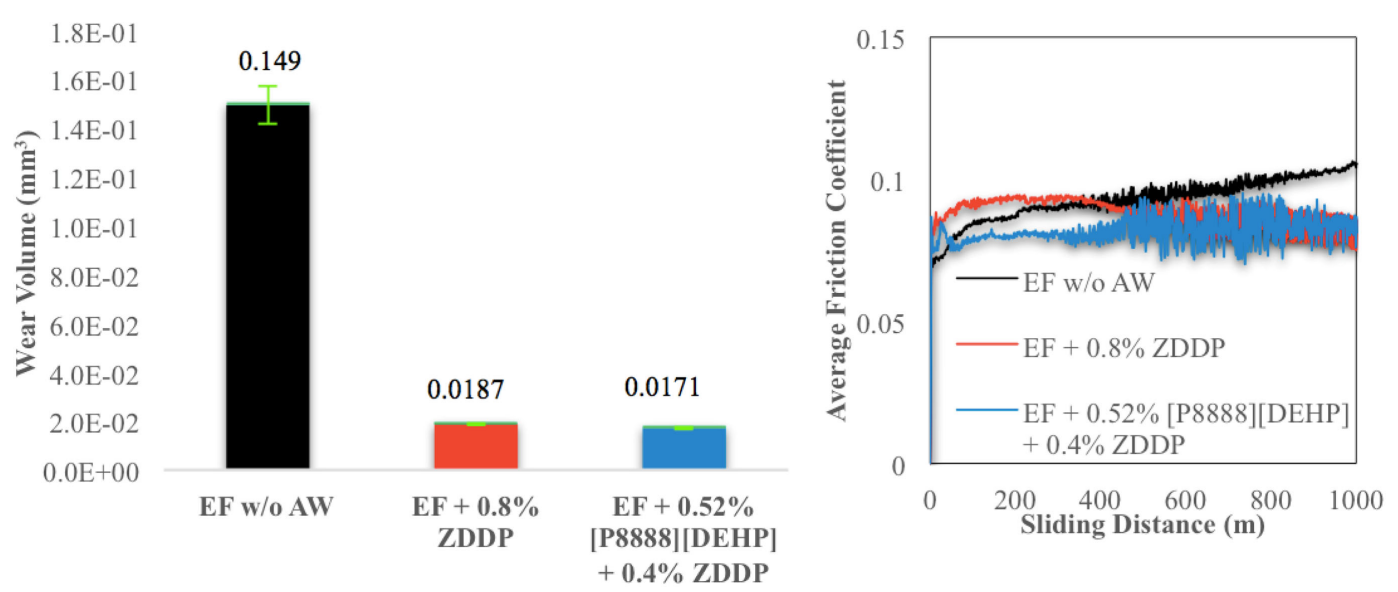

FIGURE 2 | Wear (left, 2a) and friction (right, 2b) results for reciprocating-sliding bench tests. Ball wear volumes (in green on top of each bar) and error bars are included but are very small for the second and third entries. Averaged friction results for two repetitions per lubricant. 

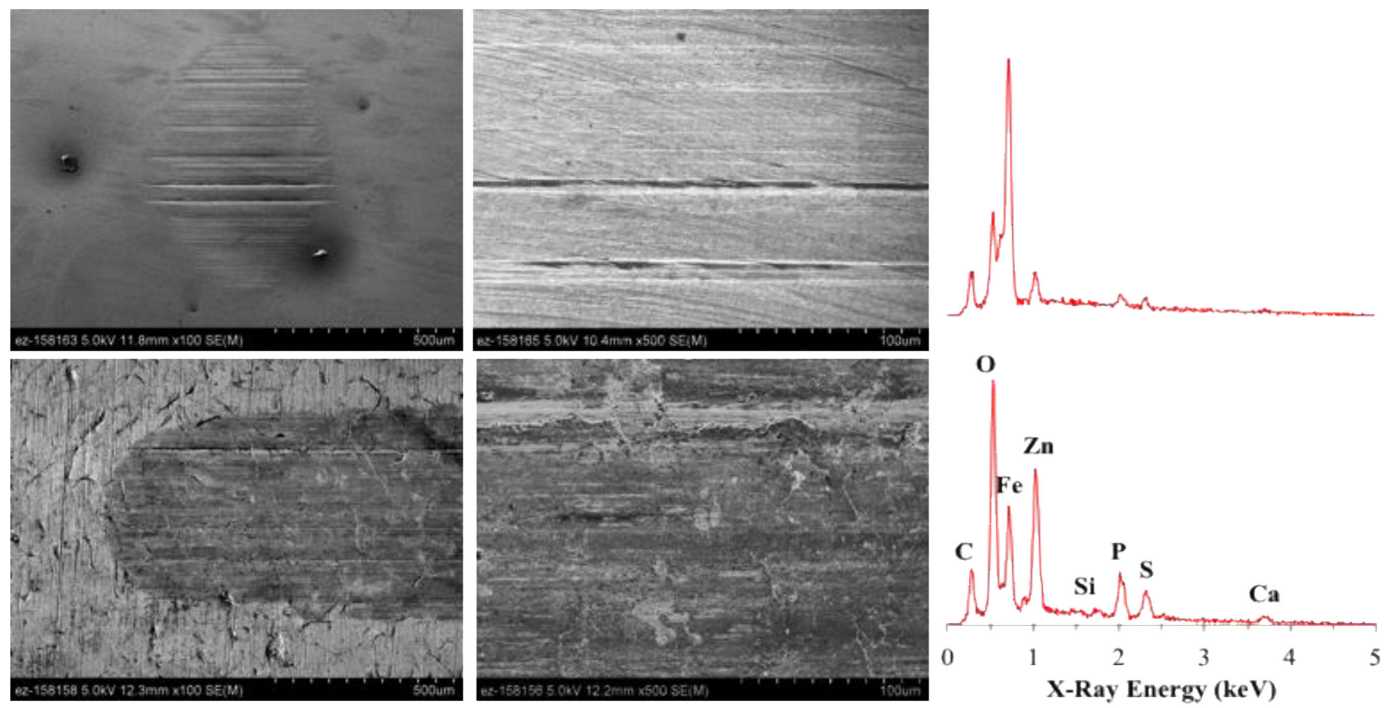

FIGURE 3 | SEM micrographs and EDS spectra of worn surfaces lubricated with EF + $\mathbf{0 . 8 \%}$ ZDDP. Top: steel ball surface. Bottom: cast iron flat surface.
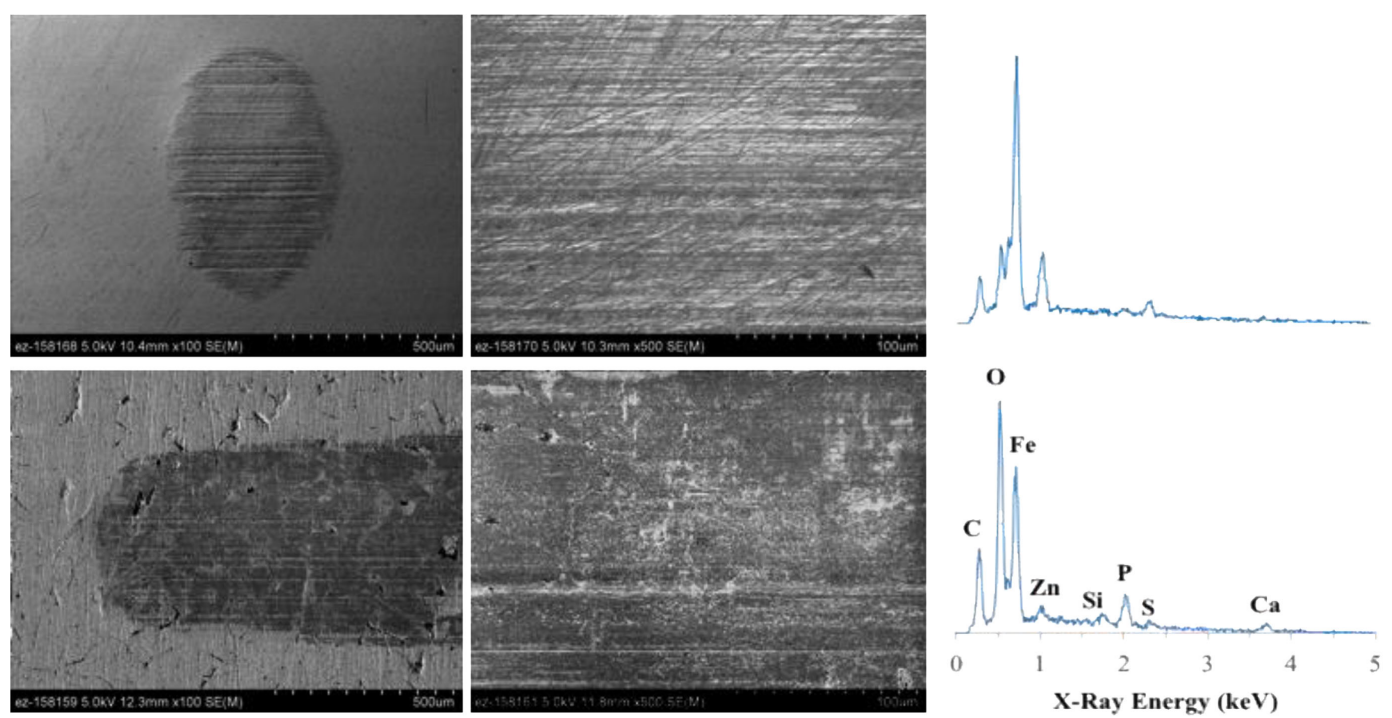

FIGURE 4 | SEM micrographs and EDS spectra of worn surfaces lubricated with EF + $\mathbf{0 . 5 2 \%}$ [P888] [DEHP] + $0.4 \%$ ZDDP. Top: steel ball surfaces.

Bottom: cast iron flat surface.

tribofilms whenever calcium-containing detergent is present in the lubricating oil with a detrimental effect on its overall AW characteristic (Nicholls et al., 2005). Figure 4 shows SEM micrographs and EDS spectra of the tribosystem lubricated with EF $+0.52 \%$ $\left[\mathrm{P}_{8888}\right][\mathrm{DEHP}]+0.4 \%$ ZDDP. The morphologies of these surfaces are visually similar to those shown in Figure 3. The elliptical ball wear scar is slightly smaller than the previous, and both ball scars show oblique wiping marks - artifacts of cleaning. The worn cast iron flat lubricated with $\mathrm{EF}+0.52 \%\left[\mathrm{P}_{8888}\right][\mathrm{DEHP}]+0.4 \% \mathrm{ZDDP}$ EDS spectrum shows a marked reduction of zinc and sulfur on the surface and an increased ratio of phosphorous to zinc suggesting both AW constituents are participating in tribofilm growth. Again, a high iron peak on the ball is observed indicating a thinner tribofilm on the steel ball. A similar amount of calcium is present compared to that in Figure 3.

\section{Mini Traction Machine Stribeck Curves}

Having verified synergy between the IL and ZDDP in the formulated oil in boundary wear and friction, we shift attention to friction behavior in a broader survey of lubrication regimes. MTM full-range speed scan Stribeck curves are shown in Figure 5, subject the tribosystem to mostly ML, some BL and EHL at a temperature of $100^{\circ} \mathrm{C}$. The SAE $20 \mathrm{~W}-30$ reference oil and $\mathrm{EF}+0.8 \% \mathrm{ZDDP}$ display very similar behavior in terms of how friction evolves as each repetition is executed. The first scan for each produced the lowest friction and the last showed the highest. 
A pattern emerges for these two blends of increasing friction as the tribofilm develops with increasing number of scans though $\mathrm{EF}+0.8 \% \mathrm{ZDDP}$ increases within a narrower band than the $20 \mathrm{~W}-$ 30 baseline oil. An opposite trend was observed for $\mathrm{EF}+0.52 \%$ $\mathrm{IL}+0.4 \%$ ZDDP as it, for the most part, showed slightly decreasing friction as the tribofilm develops and the number of scans increases. As a result, the steady-state friction curve, an average of the last 3 of 20 scans, for $\mathrm{EF}+0.52 \% \mathrm{IL}+0.4 \% \mathrm{ZDDP}$ is substantially lower than the other two lubricants as shown in the summary chart (Figure 5). EF + 0.52\% IL + 0.4\% ZDDP exhibits the highest advantage over $\mathrm{EF}+0.8 \% \mathrm{ZDDP}$ in the ML regime, but as EHL is approached, the friction curves tend to converge as expected for lubricants of the same viscosity grade.

The second set of Stribeck scans was completed with the sliding speed varied over three separate ranges as opposed to one scan over a broader range as in the previous tests. As shown in Figure 6, a similar pattern of increased friction as the tribofilm is built is noted here in both the SAE $20 \mathrm{~W}-30$ baseline and $\mathrm{EF}+0.8 \%$
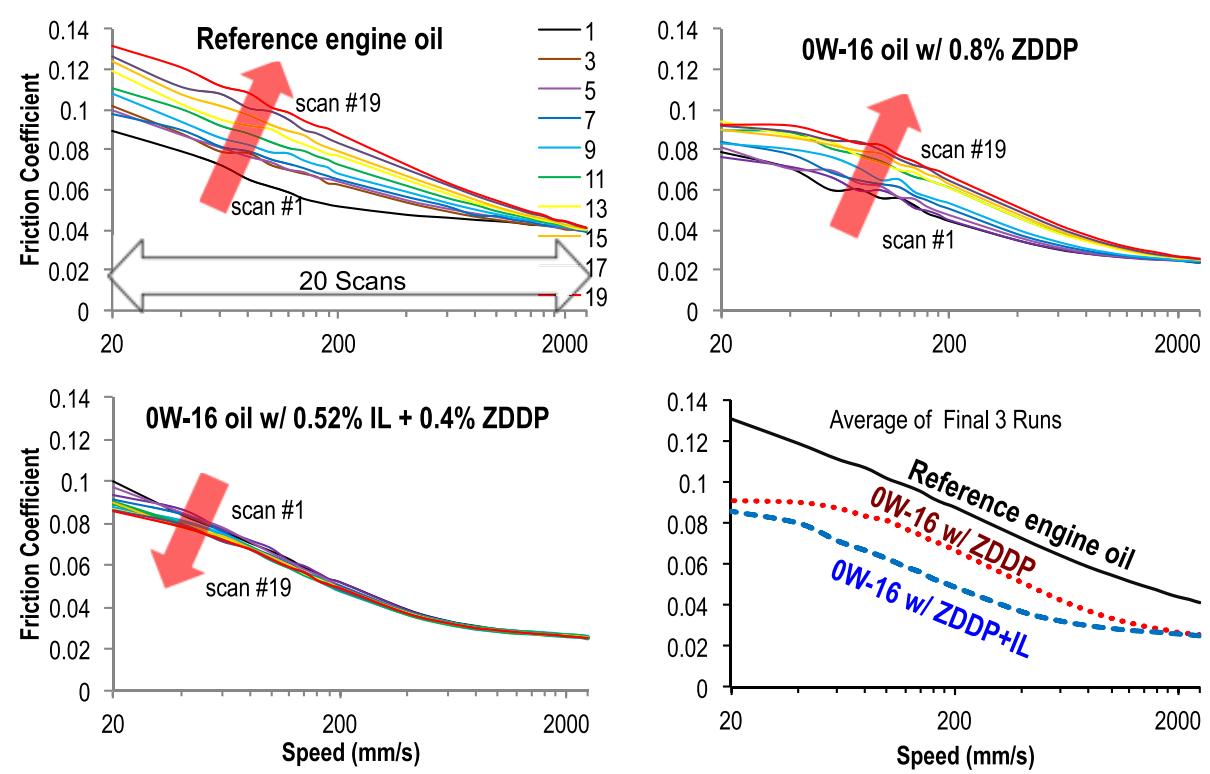

FIGURE 5 | Stribeck curves (MTM method 1). Twenty scans were completed for each blend, but only every odd repeat is shown for clarity. The summary represents the average of the final three scans for each lubricant.
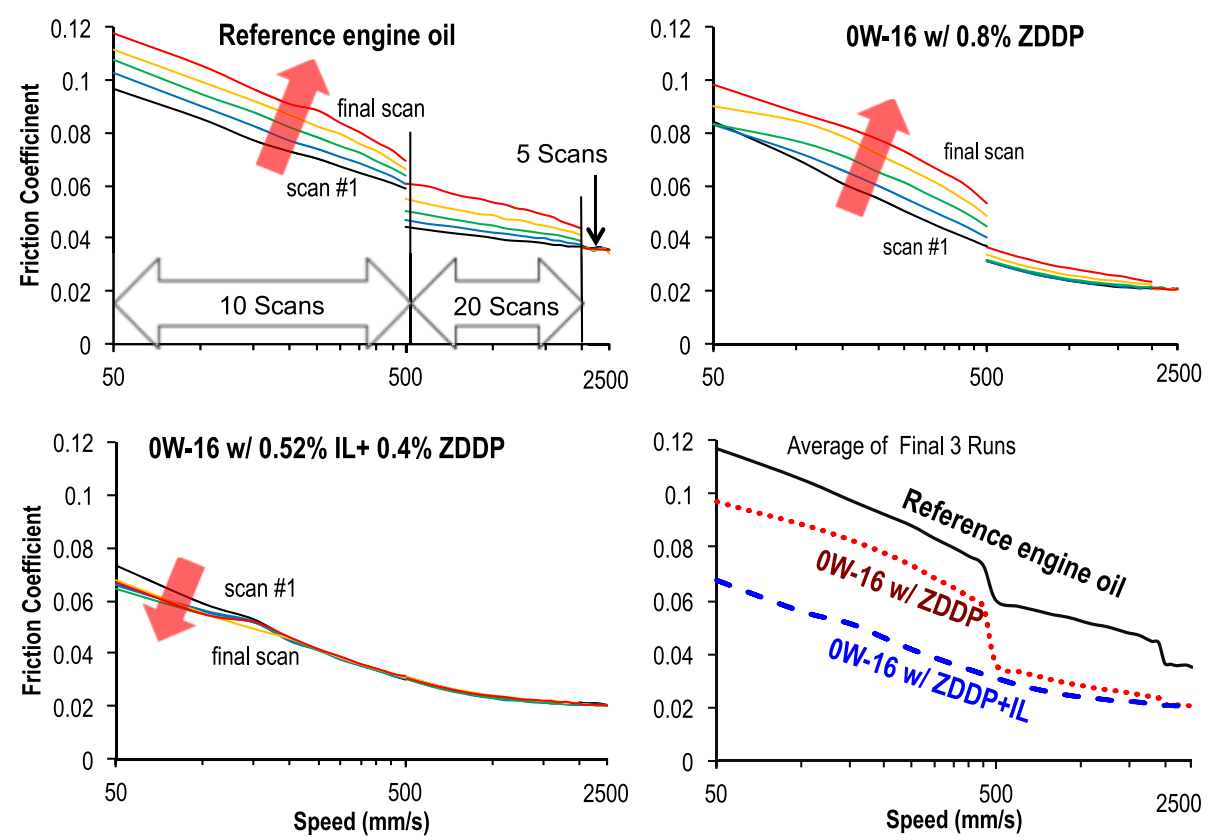

FIGURE 6 | Stribeck curves (MTM method 2). Only five scans in each speed range are shown for clarity. The summary represents the average of the final three scans for each lubricant. 
TABLE 6 | Measured arithmetic average surface roughness of balls and disks of MTM tests

\begin{tabular}{|c|c|c|c|c|}
\hline \multirow[t]{2}{*}{ Lubricant } & \multicolumn{2}{|c|}{ MTM data set 1 (Figure 5) } & \multicolumn{2}{|c|}{ MTM data set 2 (Figure 6) } \\
\hline & Disk, $R_{\mathrm{a}}(\mathrm{nm})$ & Ball, $R_{\mathrm{a}}(\mathrm{nm})$ & Disk, $R_{\mathrm{a}}(\mathrm{nm})$ & Ball, $R_{\mathrm{a}}(\mathrm{nm})$ \\
\hline$E F+0.8 \%$ ZDDP & $22.8 \pm 5.4$ & $22.3 \pm 0.9$ & $12.6 \pm 2.4$ & $24.2 \pm 4.3$ \\
\hline$E F+0.52 \% \mathrm{IL}+0.4 \% \mathrm{ZDDP}$ & $10.2 \pm 4.1$ & $21.4 \pm 1.1$ & $8.8 \pm 3.8$ & $20.7 \pm 0.5$ \\
\hline
\end{tabular}

TABLE 7 | Sequence VIE fuel economy engine test results.

\begin{tabular}{|c|c|c|c|c|c|c|c|}
\hline & Stage 1 & Stage 2 & Stage 3 & Stage 4 & Stage 5 & Stage 6 & Weighted FEI \\
\hline Lubrication regime & & EHL/HL dominant & & More BL/ML & Some BL/ML & More BL/ML & \\
\hline $\mathrm{EF}+0.8 \%$ ZDDP vs. baseline & $2.36 \%$ & $2.84 \%$ & $1.66 \%$ & $3.72 \%$ & $5.98 \%$ & $3.03 \%$ & $1.87 \%$ \\
\hline $\mathrm{EF}+0.4 \%$ ZDDP $+0.52 \%$ IL vs. baseline & $2.54 \%$ & $2.91 \%$ & $1.77 \%$ & $4.48 \%$ & $6.46 \%$ & $3.81 \%$ & $2.12 \%$ \\
\hline IL-induced improvement & $0.17 \%$ & $0.07 \%$ & $0.11 \%$ & $0.76 \%$ & $0.48 \%$ & $0.79 \%$ & $0.25 \%$ \\
\hline
\end{tabular}

ZDDP except in the third and fastest test range (EHL) in which all lubricants showed minimal variation as more repeats were completed. $\mathrm{EF}+0.52 \% \mathrm{IL}+0.4 \% \mathrm{ZDDP}$ again showed the lowest friction overall and a reduced friction coefficient as the tribofilm developed. For the average of final three scans, an even more distinct improvement was observed in ML as a result of the IL's presence.

Surface roughness for balls and disks produced in both MTM Stribeck scan sets is quantified in Table 6. Both methods show excellent correlation with the friction results in Figures 5 and $\mathbf{6}$. $\mathrm{EF}+0.52 \% \mathrm{IL}+0.4 \% \mathrm{ZDDP}$ produced smoother surfaces on both balls and disks in each case.

With very encouraging results for the IL-additized formulated oil in the previous boundary wear and friction tests and in both MTM Stribeck scan experiments, we moved forward with fullscale, multi-cylinder, fired engine fuel economy evaluation.

\section{Sequence VIE Fuel Economy Engine Dynamometer Test (FEI 1)}

Sequence VIE fuel economy engine test FEI 1 results are shown in Table 7. In agreement with bench test friction measurements, $\mathrm{EF}+0.52 \% \mathrm{IL}+0.4 \% \mathrm{ZDDP}$ demonstrated improved fuel economy in all six stages of the Sequence VIE compared with the baseline by $2.12 \%$ and $\mathrm{EF}+0.8 \%$ ZDDP by $0.25 \%$, respectively. Stages $4-6$, which constitute $35.7 \%$ of the final weighted score, subject the test engine to increased levels of BL and ML regimes; under these conditions there is more pronounced benefit as a result of adding the IL $(0.76,0.48$, and $0.79 \%$ for Stages $4-6$ respectively) compared to ZDDP only. On the other hand, Stages 1-3 show smaller IL-induced improvements because EHL and HL are the dominant lubrication regimes. These test results indicate that an IL, such as $\left[\mathrm{P}_{8888}\right][\mathrm{DEHP}]$, can function in tandem with ZDDP in an AW context and reduce the friction between engine components in the Sequence VIE assessment thus improving fuel economy across a spectrum of engine operating conditions.

\section{References}

Barnes, A. M., Bartle, K. D., and Thibon, V. R. A. (2001). A review of zinc dialkyldithiophosphates (ZDDPS): characterisation and role in the lubricating oil. Tribol. Int. 34, 389-395. doi:10.1016/S0301-679X(01)00028-7

\section{Conclusions}

In this work, we have demonstrated the effectiveness of applying an oil-miscible phosphonium-organophosphate IL in conjunction with a secondary ZDDP to fulfill an AW and friction-reducing role as an additive in an experimentally formulated SAE $0 \mathrm{~W}-16$ engine oil. Through BL bench tests, we have shown that the combination of the IL and ZDDP in formulated oil is more effective in wear protection than using ZDDP only. Two types of Stribeck curve measurements showed marked IL-induced friction reduction in the mixed and boundary regimes. The full-scale engine fuel economy dynamometer experiments provided direct evidence of fuel economy improvement as a result of adding IL in formulated oil in a Sequence VIE engine test with weighted FEI of 2.12 and $0.25 \%$ over the reference oil and ZDDP-only formulation, respectively. The strong correlation between the bench and engine test results suggests promising potential for the IL additive technology.

\section{Acknowledgments}

The authors would like to thank A. Alfonso from Intertek Automotive Research for performing the Sequence VIE engine tests, P. Bastien from Shell Global Solutions (US) Inc. for low viscosity experimental engine oil blending, and Dr. J. Dyck from Cytec Industries Inc. for providing phosphonium cation feed stocks. This research was sponsored by the Vehicle Technologies Office, Office of Energy Efficiency and Renewable Energy, U.S. Department of Energy (DOE). Notice: This report has been authored by UT-Battelle, LLC, under Contract No. DE-AC05-00OR22725 with the U.S. Department of Energy. The United States Government retains and the publisher, by accepting the article for publication, acknowledges that the United States Government retains a nonexclusive, paid-up, irrevocable, world-wide license to publish or reproduce the published form of this manuscript, or allow others to do so, for United States Government purposes.
Barnhill, W. C., Qu, J., Luo, H., Meyer, H. M., Ma, C., Chi, M., et al. (2014). Phosphonium-organophosphate ionic liquids as lubricant additives: effects of cation structure on physicochemical and tribological characteristics. ACS Appl. Mater. Interfaces. 6, 22585-22593. doi:10.1021/ am506702u 
Bermúdez, M.-D., Jiménez, A.-E., Sanes, J., and Carrión, F.-J. (2009). Ionic liquids as advanced lubricant fluids. Molecules 14, 2888-2908. doi:10.3390/ molecules 14082888

Cai, M., Liang, Y., Yao, M., Xia, Y., Zhou, F., and Liu, W. (2010). Imidazolium ionic liquids as antiwear and antioxidant additive in poly (ethylene glycol) for steel/steel contacts. ACS Appl. Mater. Interfaces 2, 870-876. doi:10.1021/ am900847j

Chen, Y. M., Zeng, Z. X., Yang, S. R., and Zhang, J. Y. (2009). The tribological performance of BCN films under ionic liquids lubrication. Diamond Relat. Mater. 18, 20-26. doi:10.1016/j.diamond.2008.07.023

D7589-15 A. (2015). Standard Test Method for Measurement of Effects of Automotive Engine Oils on Fuel Economy of Passenger Cars and Light-Duty Trucks in Sequence VID Spark Ignition Engine. West Conshohocken, PA: ASTM International.

Dreyfus, M. K., and Viscusi, W. K. (1995). Rates of time preference and consumer valuations of automobile safety and fuel efficiency. J. Law Econ. 38, 79-105. doi: $10.1086 / 467326$

Forsyth, M., Kemp, T. F., Howlett, P. C., Sun, J., and Smith, M. E. A. (2008). Potential novel rapid screening NMR approach to boundary film formation at solid interfaces in contact with ionic liquids. J. Phys. Chem. C 112, 13801-13804. doi:10.1021/jp806096w

González, R., Hernández Battez, A., Blanco, D., Viesca, J. L., and FernándezGonzález, A. (2010). Lubrication of TiN, CrN and DLC PVD coatings with 1butyl-1-methylpyrrolidinium tris(pentafluoroethyl)trifluorophosphate. Tribol. Lett. 40, 269-277. doi:10.1007/s11249-010-9674-5

Holmberg, K., Andersson, P., and Erdemir, A. (2012). Global energy consumption due to friction in passenger cars. Tribol. Int. 47, 221-234. doi:10.1016/j.triboint. 2011.11.022

Jiménez, A. E., Bermúdez, M. D., Iglesias, P., Carrión, F. J., and Martínez-Nicolás, G. (2006). 1-N-alkyl-3-methylimidazolium ionic liquids as neat lubricants and lubricant additives in steel-aluminium contacts. Wear 260, 766-782. doi:10. 1016/j.wear.2005.04.016

Libardi, A., Schmid, S. R., Sen, M., and Schneider, W. (2013). Evaluation of ionic fluids as lubricants in manufacturing. J. Manuf. Process. 15, 414-418. doi:10. 1016/j.jmapro.2013.06.005

Liu, W., Ye, C., Gong, Q., Wang, H., and Wang, P. (2002). Tribological performance of room-temperature ionic liquids as lubricant. Tribol. Lett. 13, 81-85. doi:10. 1023/A:1020148514877

Liu, X., Zhou, F., Liang, Y., and Liu, W. (2006). Tribological performance of phosphonium based ionic liquids for an aluminum-on-steel system and opinions on lubrication mechanism. Wear 261, 1174-1179. doi:10.1016/j.wear.2006.03.018

Lu, R., Nanao, H., Kobayashi, K., Kubo, T., and Mori, S. (2010). Effect of lubricant additives on tribochemical decomposition of hydrocarbon oil on nascent steel surfaces. J. Jpn. Pet. Inst. 53, 55-60. doi:10.1627/jpi.53.55

Minami, I. (2009). Ionic liquids in tribology. Molecules 14, 2286-2305. doi:10.3390/ molecules14062286

Minami, I., Inada, T., Sasaki, R., and Nanao, H. (2010). Tribo-chemistry of phosphonium-derived ionic liquids. Tribol. Lett. 40, 225-235. doi:10.1007/ s11249-010-9626-0

Mistry, K., Fox, M., and Priest, M. (2009). Lubrication of an electroplated nickel matrix silicon carbide coated eutectic aluminium-silicon alloy automotive cylinder bore with an ionic liquid as a lubricant additive. Proc. Inst. Mech. Eng. Part J. 223, 563-569. doi:10.1243/13506501JET562

Mu, Z., Liu, W., Zhang, S., and Zhou, F. (2004). Functional room-temperature ionic liquids as lubricants for an aluminum-on-steel system. Chem. Lett. 33, 524-525. doi:10.1246/cl.2004.524

Nicholls, M. A., Do, T., Norton, P. R., Kasrai, M., and Bancroft, G. M. (2005). Review of the lubrication of metallic surfaces by zinc dialkyl-dithiophosphates. Tribol. Int. 38, 15-39. doi:10.1016/j.triboint.2004.05.009

Otero, I. S., López, E. R., Reichelt, M., Villanueva, M., Salgado, J., and Fernández, J. (2014). Ionic liquids based on phosphonium cations as neat lubricants or lubricant additives for a steel/steel contact. ACS Appl. Mater. Interfaces 6, 13115-13128. doi:10.1021/am502980m

Palacio, M., and Bhushan, B. A. (2010). Review of ionic liquids for green molecular lubrication in nanotechnology. Tribol. Lett. 40, 247-268. doi:10.1007/s11249010-9671-8

Phillips, B. S., and Zabinski, J. S. (2004). Ionic liquid lubrication effects on ceramics in a water environment. Tribol. Lett. 17, 533-541. doi:10.1023/B:TRIL. 0000044501.64351 .68
Qu, J., Bansal, D. G., Yu, B., Howe, J. Y., Luo, H., Dai, S., et al. (2012). Antiwear performance and mechanism of an oil-miscible ionic liquid as a lubricant additive. ACS Appl. Mater. Interfaces 4, 997-1002. doi:10.1021/am201646k

Qu, J., Barnhill, W. C., Luo, H., Meyer, H. M., Leonard, D. N., Landauer, B. A., et al. (2015). Synergistic effects between phosphonium-organophosphate ionic liquids and ZDDP as lubricant additives. Adv. Mater. Weinheim 27, 4767-4774. doi:10.1002/adma.201502037

Qu, J., Blau, P. J., Dai, S., Luo, H., and Meyer, H. M. (2009). Ionic liquids as novel lubricants and additives for diesel engine applications. Tribol. Lett. 35, 181-189. doi:10.1007/s11249-009-9447-1

Qu, J., Luo, H., Chi, M., Ma, C., Blau, P. J., Dai, S., et al. (2014). Comparison of an oil-miscible ionic liquid and ZDDP as a lubricant anti-wear additive. Tribol. Int. 71, 88-97. doi:10.1021/am201646k

Qu, J., Truhan, J., Dai, S., Luo, H., and Blau, P. (2006). Ionic liquids with ammonium cations as lubricants or additives. Tribol. Lett. 22, 207-214. doi:10.1007/s11249006-9081-0

Qu, J., Truhan, J. J. Jr, Dai, S., Luo, H., and Blau, P. J. (2010). Lubricants or Lubricant Additives Composed of Ionic Liquids Containing Ammonium Cations. Google Patents.

Schneider, A., Brenner, J., Tomastik, C., and Franek, F. (2010). Capacity of selected ionic liquids as alternative EP/AW additive. Lubr. Sci. 22, 215-223. doi:10.1002/ ls. 120

Shah, F. U., Glavatskih, S., MacFarlane, D. R., Somers, A., Forsyth, M., and Antzutkin, O. N. (2011). Novel halogen-free chelated orthoboratephosphonium ionic liquids: synthesis and tribophysical properties. Phys. Chem. Chem. Phys. 13, 12865-12873. doi:10.1039/clcp21139k

Shiau, C.-S. N., Michalek, J. J., and Hendrickson, C. T. (2009). A structural analysis of vehicle design responses to corporate average fuel economy policy. Transport. Res. A 43, 814-828. doi:10.1016/j.tra.2009.08.002

Somers, A., Howlett, P., Sun, J., MacFarlane, D., and Forsyth, M. (2010a). Transition in wear performance for ionic liquid lubricants under increasing load. Tribol. Lett. 40, 279-284. doi:10.1007/s11249-010-9695-0

Somers, A. E., Khemchandani, B., Howlett, P. C., Sun, J., MacFarlane, D. R., and Forsyth, M. (2013). Ionic Liquids as antiwear additives in base oils: influence of structure on miscibility and antiwear performance for steel on aluminum. ACS Appl. Mater. Interfaces 5, 11544-11553. doi:10.1021/am4037614

Somers, A., Howlett, P., Sun, J., MacFarlane, D., and Forsyth, M. (2010b). "Phosphonium ionic liquids as lubricants for aluminium-steel," in Tribology Des. 66, 273-283. doi:10.2495/TD100231

Tung, S. C., and McMillan, M. L. (2004). Automotive tribology overview of current advances and challenges for the future. Tribol. Int. 37, 517-536. doi:10.1016/j. triboint.2004.01.013

Weng, L., Liu, X., Liang, Y., and Xue, Q. (2007). Effect of tetraalkylphosphonium based ionic liquids as lubricants on the tribological performance of a steel-onsteel system. Tribol. Lett. 26, 11-17. doi:10.1007/s11249-006-9175-8

Yao, M., Liang, Y., Xia, Y., and Zhou, F. (2009). Bis-imidazolium ionic liquids as the high performance anti-wear additives in polyethylene glycol for steel-steel contacts. ACS Appl. Mater. Interfaces 1, 467-471. doi:10.1021/am800132z

Ye, C., Liu, W., Chen, Y., and Yu, L. (2001). Room-temperature ionic liquids: a novel versatile lubricant. Chem. Commun. 21, 2244-2245. doi:10.1039/b106935g

Yu, B., Bansal, D. G., Qu, J., Sun, X., Luo, H., Dai, S., et al. (2012). Oil-miscible and non-corrosive phosphonium-based ionic liquids as candidate lubricant additives. Wear 289, 58-64. doi:10.1016/j.wear.2012.04.015

Zhou, Y., Dyck, J., Graham, T. W., Luo, H., Leonard, D. N., and Qu, J. (2014). Ionic liquids composed of phosphonium cations and organophosphate, carboxylate, and sulfonate anions as lubricant antiwear additives. Langmuir 30, 13301-13311. doi:10.1021/la5032366

Conflict of Interest Statement: The authors declare that the research was conducted in the absence of any commercial or financial relationships that could be construed as a potential conflict of interest.

Copyright (c) 2015 Barnhill, Gao, Kheireddin, Papke, Luo, West and Qu. This is an open-access article distributed under the terms of the Creative Commons Attribution License (CC BY). The use, distribution or reproduction in other forums is permitted, provided the original author(s) or licensor are credited and that the original publication in this journal is cited, in accordance with accepted academic practice. No use, distribution or reproduction is permitted which does not comply with these terms. 